\title{
Correlations between the right ventricular passive elasticity and organ function in adult ovine
}

\author{
Wenqiang Liu ${ }^{1}$, Michael Nguyen-Truong ${ }^{1}$, Kevin Labus ${ }^{2}$, June Boon ${ }^{3}$, Jeremiah Easley ${ }^{3}$ Eric Monnet ${ }^{3}$, Christian Puttlitz ${ }^{1,2}$ and Zhijie \\ Wang ${ }^{1,2 *}$ \\ ${ }^{1}$ School of Biomedical Engineering, Colorado State University, Fort Collins, Colorado, USA \\ ${ }^{2}$ Department of Mechanical Engineering, Colorado State University, Fort Collins, Colorado, USA \\ ${ }^{3}$ Department of Veterinary Medicine and Biomedical Sciences, Colorado State University, Fort Collins, Colorado, USA
}

\begin{abstract}
Right ventricle failure (RVF) contributes significantly to the morbidity and mortality in pulmonary hypertension (PH). The mechanical behavior of the RV is considered fundamental to its physiological function; however, the link between RV tissue biomechanics and organ function remains a key knowledge gap. We hypothesize that the RV passive elasticity is correlated with its in vivo function. In this study, we examined the relationships between the tissue mechanics and physiological function of the RV in healthy and $\mathrm{PH}$ sheep using a revised ovine model of pulmonary artery constriction. In vivo RV function was examined by echocardiography and hemodynamic measurement, and the RV passive elasticity was measured by ex vivo equibiaxial mechanical tests. We observed that the RV longitudinal stiffness was significantly increased and thus the anisotropic property was altered in PH sheep. This elasticity was significantly correlated with the long axis end-diastolic or end-systolic diameter/area. We further observed that in the outflow tract (longitudinal) direction, there were trends of correlations between the low-strain elastic modulus (EM) and the acceleration time, as well as between the high-strain EM and the deceleration time. These findings strongly indicate the critical role of RV passive mechanical properties in the organ function.
\end{abstract}

\section{Introduction}

Right ventricle failure (RVF) contributes significantly to the mortality and morbidity in a variety of cardiovascular diseases including pulmonary hypertension $(\mathrm{PH})$, congenital heart disease and left heart failure with preserved ejection fraction [1-5]. The biomechanical properties of the RV free wall are considered to play a role in its organ function [6,7], and a recent rodent study has reported a correlation between the passive elastic modulus and the end-diastolic volume of the RV [8], with the latter often being used as an index of RV function [9]. This is the first study that directly relates the RV tissue mechanics to a clinically relevant hemodynamic index, leading to a new point of view to link the ventricular biomechanics with the organ function to advance the understanding of biomechanical mechanism of RV failure. However, the comprehensive understanding of the roles of RV biomechanical properties in the in vivo function remains a key knowledge gap.

This study aimed to explore the correlations between RV tissue mechanical properties and the in vivo function in healthy and hypertensive adults. We hypothesized that the RV passive elasticity was correlated with its in vivo function. Using a large animal model of RV failure, we observed the correlations between the RV elastic properties and the physiological function, and our findings offer a deepened insight of the biomechanical mechanisms of RVF secondary to chronic pressure overload.

\section{Materials and methods}

Ovine model of pulmonary hypertension and RV failure development

All animal works were approved by the Colorado State University
Institutional Animal Care and Use Committee (IACUC\#17-7590A). Six $\mathrm{PH}$ sheep and three age-matched health sheep were recruited in this study. Sheep was chosen for this study because its anatomy and physiology are closer to human than those of small animals [10]. PH was induced in eight-month old male and female ovine using our recently established animal-specific, pulmonary artery constriction model [11]. Briefly, an adjustable hydraulic occluder (AUS-PORT $12 \times 14 \mathrm{~mm}$, Norfolk Vet Products, IL) was placed around the main pulmonary artery trunk to elevate the pulmonary pressure. The degree of constriction for each animal was determined by the amount of saline injected to elevate the RV systolic pressure comparable to that of the left ventricle (LV) in the same animal. The chronic pressure overload was maintained for 11-20 weeks and thus different phases of RV failure were included in these $\mathrm{PH}$ ovine.

\section{In vivo functional measurements}

Prior to the euthanasia, RV hemodynamic and function measurements were performed by thoracic echocardiography using a 2.5 MHz transducer on a GE Vivid (GE Healthcare, Chicago, IL) in awake animals, and then by RV catheterization (7 Fr Swan Ganz catheter (Edwards Lifesciences Corporation, Irvine, CA) in anesthetized animals. RV systolic pressure (RVSP), stroke volume $(\mathrm{SV})$, cardiac output (CO), tricuspid annular plane systolic excursion

${ }^{\star}$ Correspondence to: Zhijie Wang, School of Biomedical Engineering, Colorado State University, Fort Collins, Colorado, USA, E-mail: zhijie.wang@colostate.edu

Key words: cardiac mechanics, stiffness, pulmonary hypertension, pressure overload, $R V$ dysfunction

Received: July 22, 2020; Accepted: August 07, 2020; Published: August 17, 2020 
(TAPSE), fraction shortening (FS), acceleration time (AT), deceleration time (DT) and ejection time (ET) were obtained [11]. RV diameters and areas at end-diastolic and end-systolic phases were measured. After euthanasia, RV hypertrophy was measured by Fulton index, which is the ratio of wet tissue weights calculated as $\mathrm{RV} /(\mathrm{LV}+\mathrm{S})$, where $\mathrm{LV}$ is the left ventricle and $S$ is the septum [12].

\section{Ex vivo mechanical test and data analysis}

Within four hours of sacrifice, the RVs were dissected and immersed in a physiological saline solution (PBS) on ice. Because the healthy RV is thin, almost the entire free wall was used for mechanical tests after the removal of trabeculae; but in diseased RVs, the midwall was sliced with a similar thickness of healthy RVs and used for mechanical tests. To obtain the biaxial mechanical properties, the outflow tract (OT) direction of the RV was defined as the longitudinal direction in the test axis. A minimal sample aspect ratio of 3:1 (length: thickness) was used to approximate a plane-stress condition, and a cruciform section (with the center square region to be $25 \mathrm{~mm} \times 25 \mathrm{~mm} \times 3 \mathrm{~mm}$ ) was cut to generate more homogenous strain distribution and minimize shear strains in the biaxial tests $[13,14]$. A ruler and caliper were used to measure the tissue size and thickness, respectively.

The tissues then underwent equibiaxial tensile mechanical tests, either with a regular spray of PBS solution to keep the tissue moist in room air or with the bath of cardioplegic solution (CPS) and $30 \mathrm{mM}$ of 2,3-butanedione monoxime $(\mathrm{BDM})$ at $26-37^{\circ} \mathrm{C}$. Our supplement experimental data confirmed that there were not significant changes of the stress-strain curves between these testing conditions (Figure 1). Graphite powder (AGS, MI) was used for strain characterization via digital image correlation. During the test, images were taken with a digital camera (Nikon) at $1 \mathrm{fps}$. A MATLAB-based digital imagine correlation program was used to analyze the tissue deformation. Two $250 \mathrm{lb}$ capacity load cells (Honeywell Sensotec, Columbus, OH) were used to obtain the forces. A custom LabVIEW code was used to control the actuators and record the data [13].

After mounting, a small preload $(\sim 0.1 \mathrm{~N})$ was applied to define the zero-stress configuration, and then the tissue underwent 15 cycles equibiaxial tests including preconditioning cycles (at the stretch rate of $15 \mathrm{~mm} / \mathrm{min}$, with $\sim 25 \%$ maximal stretch). Assuming the tissue to be incompressible [15] and with negligible shear deformation, the last cycle of the loading curve was then used to generate the Cauchy stress-Green strain curve to analyze the RV mechanical properties as previously described [15]. We were unable to obtain complete mechanical data in one control and one PH sheep. From the stress-strain curves, the RV passive stiffness (or elasticity) was quantified by the elastic moduli (EM) at the low and high strain ranges, respectively [8].

\section{Statistical and correlation analyses}

All data were analyzed by the non-parametric statistical analysis, except for the EM which were confirmed with the normal distribution by the QQ plot (GraphPad (v8.0.2)). Pearson correlation analysis was used to investigate the correlations between the tissue mechanical properties and RV function indices (Microsoft Excel). All the data were presented as mean \pm SEM. $\mathrm{P}<0.05$ was considered statistically significant.

\section{Results}

\section{Changes in RV geometry and hemodynamic function with PH development}

The results of the individual RV geometry and hemodynamic function were summarized in Table 1 . There was a significant increase in RVSP and significant decreases in SV and CO in the $\mathrm{PH}$ group compared to the CTL group $(\mathrm{p}<0.05)$. $\mathrm{PH}$ also led to a trend of decrease in the AT ( $\mathrm{p}=0.07)$ and significant increases in the DT, ET, as well as the AT/ET ratio compared to the CTL group $(\mathrm{p}<0.05)$. Lastly, the RV became significantly hypertrophic with the $\mathrm{PH}$ development $(\mathrm{p}<0.05)$. These results indicate the successful induction of pressure overload of the RV and the establishment of RV failure in the PH animals.

\section{Changes in RV passive elasticity with $\mathrm{PH}$ development}

Figure 2 presented the RV passive, biaxial elasticity obtained from the control and $\mathrm{PH}$ ovine. Despite a relative small number of the control animals, we observed significant stiffening of the RV in the $\mathrm{PH}$ group: compared to the control RVs, the PH RVs had a larger EM at low strain range $\left(\mathrm{EM}_{\mathrm{Low}}\right)$ in the longitudinal direction (Figure $\left.\left.2 \mathrm{~A}\right), \mathrm{p}<0.05\right)$. A similar trend was observed for the EM at high strain range $\left(\mathrm{EM}_{\mathrm{High}}\right)$ in the same direction, but the difference did not reach statistical significance (Figure 2B). In contrast, the changes in these EM in the circumferential direction were absent with $\mathrm{PH}$ development.

Furthermore, $\mathrm{PH}$ led to a strong trend of increased $\mathrm{EM}_{\text {Low }}$ in the longitudinal direction compared to the circumferential direction (Figure 2A, $\mathrm{p}=0.06$ ). However, this was not observed in the control
A

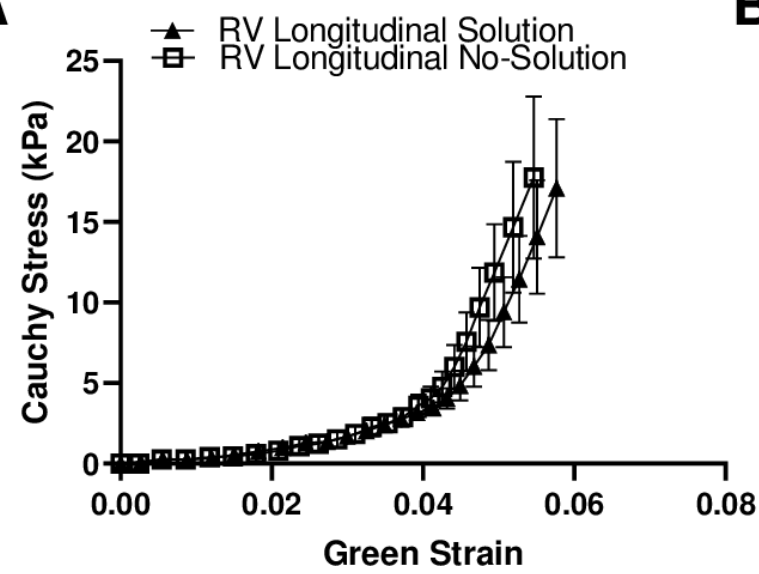

B

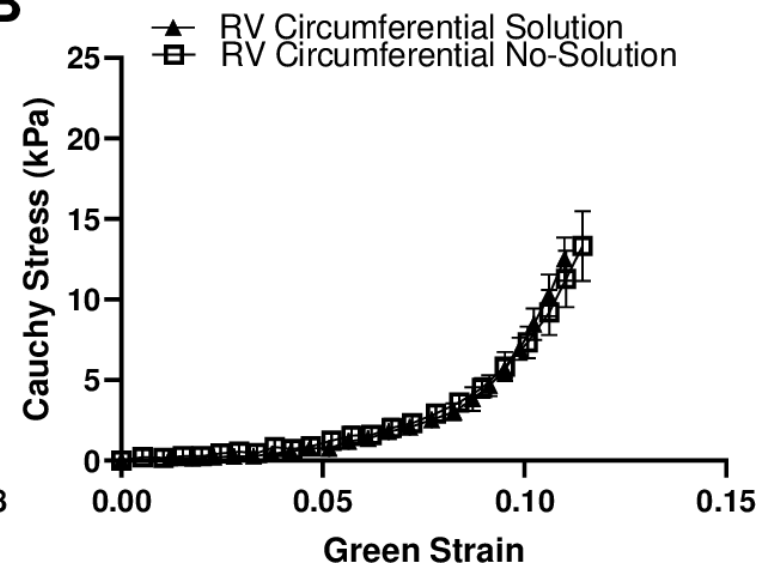

Figure 1. Comparison of the average stress-stain curves obtained from different testing conditions. (A-B) stress-strain curves in the longitudinal and circumferential directions, respectively. $\mathrm{N}=3$. 
Table 1. Individual hemodynamics, structure and function measurements of the ovine RV.

\begin{tabular}{|c|c|c|c|c|c|c|c|c|c|c|}
\hline Sample & $\begin{array}{c}\text { RVSP } \\
(\mathrm{mmHg})\end{array}$ & $\begin{array}{c}\text { SV } \\
(\mathrm{mL})\end{array}$ & $\begin{array}{c}\text { CO } \\
(\mathrm{mL})\end{array}$ & $\begin{array}{c}\text { TAPSE } \\
(\mathrm{mm})\end{array}$ & $\begin{array}{l}\text { FS } \\
(\%)\end{array}$ & $\begin{array}{c}\mathbf{A T} \\
(\mathrm{msec})\end{array}$ & $\begin{array}{c}\text { ET } \\
(\mathrm{msec})\end{array}$ & $\begin{array}{c}\text { DT } \\
(\mathrm{msec})\end{array}$ & $\mathbf{A T} / \mathbf{E T}$ & $\begin{array}{c}\text { Fulton Index } \\
(\%)\end{array}$ \\
\hline CTL1 & 22.7 & 96 & 9.2 & 19 & I & 94 & 231 & 137 & 0.41 & 28.8 \\
\hline CTL2 & 23.8 & 99 & 13.3 & 21 & I & 73 & 160 & 87 & 0.46 & 29.5 \\
\hline CTL3 & 21.7 & 130 & 11.6 & 28 & I & 68 & 198 & 130 & 0.34 & 27 \\
\hline Mean \pm SEM & $23 \pm 1$ & $108 \pm 11$ & $11 \pm 1$ & $23 \pm 3$ & I & $78 \pm 8$ & $196 \pm 21$ & $118 \pm 16$ & $0.40 \pm 0.03$ & $28 \pm 1$ \\
\hline PH1 & 35 & 69 & 6.5 & 17 & 32.7 & I & 321 & I & I & 43.9 \\
\hline PH2 & 51 & 65 & 5.9 & 20 & 11.1 & 69 & 335 & 266 & 0.21 & 46 \\
\hline PH3 & 45 & 83 & 9.4 & 22 & I & 59 & 237 & 178 & 0.25 & 39.2 \\
\hline PH4 & 42 & 39 & 3.8 & 25 & 35.9 & 62 & 271 & 209 & 0.23 & 58.8 \\
\hline PH5 & 28 & 56 & 5.6 & 22 & 11.9 & 67 & 360 & 293 & 0.19 & 58.2 \\
\hline PH6 & 51 & 47 & 3.9 & 20 & 27 & 44 & 278 & 234 & 0.16 & 64.1 \\
\hline Mean \pm SEM & $42 \pm 4 *$ & $60 \pm 7^{*}$ & $6 \pm 1 *$ & $21 \pm 1$ & $24 \pm 5$ & $60 \pm 4$ & $300 \pm 19^{*}$ & $236 \pm 20^{*}$ & $0.21 \pm 0.02 *$ & $52 \pm 4^{*}$ \\
\hline
\end{tabular}

CTL: Control Group, PH: Pulmonary Hypertension Group. RVSP: Right Ventricle Systolic Pressure, SV: Stroke Volume, CO: Cardiac Output; TAPSE: Tricuspid Annular Plane Systolic Excursion, FS: Fraction Shortening, AT: Accelerate Time And ET: Ejection Time. /: unable to obtain the data. *: p < 0.05 vs CTL group.
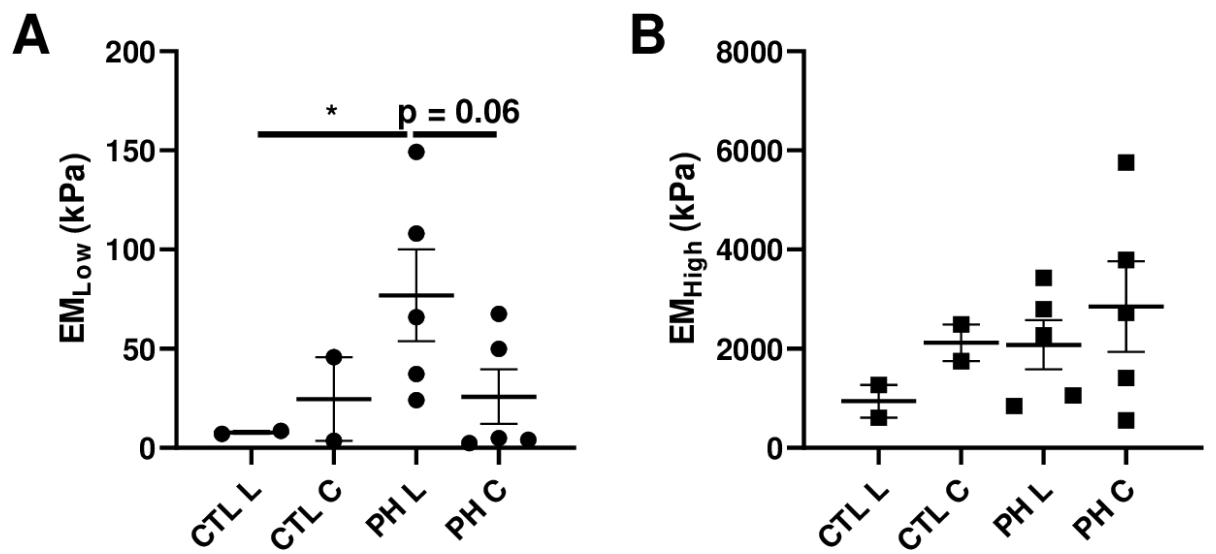

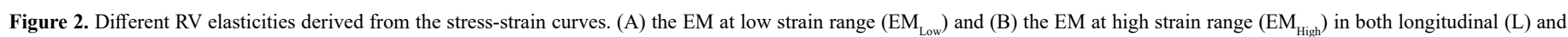
circumferential (C) directions. CTL: control group, PH: pulmonary hypertension group. *: $\mathrm{p}<0.05$.

RVs. These results indicate an alteration of the anisotropic behavior at the low strain range with the progression of $\mathrm{PH}$. We did not observe any anisotropic behavior from the high-strain EM in both $\mathrm{PH}$ and control groups.

Correlations between RV passive elasticity and physiological function indices

RV elasticity and RV diameter: Among all healthy and diseased RVs, we observed that the longitudinal $\mathrm{EM}_{\text {Low }}$ was significantly correlated with the long-axis end-diastolic area (Figure 3A), $\mathrm{p}<0.05$ and it tended to correlate with the end-systolic diameter (Figure 3B). Moreover, we also saw a trend that the longitudinal $\mathrm{EM}_{\mathrm{High}}$ was correlated with the long-axis RV end-systolic diameter (Figure 3C). In our study, the definition of longitudinal direction in the biaxial properties was anatomical and aligned with the long-axis of the RV geometry. Thus, these data suggest that the passive elasticity of the RV is strongly related to the ventricular shortening in the same (long-axis) direction.

RV elasticity and RV area: Similarly, as we observed in the RV diameter, the longitudinal $\mathrm{EM}_{\text {Low }}$ was significantly correlated with the long-axis RV end-systolic area (Figure 4A), $\mathrm{p}<0.05$ and it tended to correlate with the RV end-diastolic area (Figure 4B). However, the $\mathrm{EM}_{\text {High }}$ was differently correlated with the RV area than with the RV diameter: instead of the longitudinal $\mathrm{EM}_{\mathrm{High}}$, the circumferential $\mathrm{EM}_{\mathrm{High}}$ showed a trend of correlation with the long-axis RV end-systolic area (Figure 4C).
RV elasticity and RV hemodynamic profile: Lastly, we found that the RV longitudinal stiffness indices showed strong trends of correlations with the RV hemodynamic profile obtained from the Doppler flow measurements. The longitudinal $\mathrm{EM}_{\text {Low }}$ tended to be negatively correlated with the AT, and the longitudinal $\mathrm{EM}_{\text {High }}$ tended to be positively correlated with the ET and DT (Figure 5).

Moreover, we examined the correlations between the RV passive elasticity and other function indices such as the SV and TAPSE. We observed a mild trend of negative correlation between the longitudinal $\mathrm{EM}_{\text {High }}$ and the SV ( $\left.\mathrm{r}=-0.48, \mathrm{p}=0.28\right)$, but there were no correlations between the passive elasticity indices and TAPSE (data not shown).

\section{Discussion}

In this study, we originally investigated the relationship between RV passive mechacnial property and its physiological function in healthy and pulmonary hypertensive adults using a sheep model of RV failure. To our knowledge, there is only one rodent study showing a correlation between the RV passive elasticity and its enddiastolic volume [8]. The prior study was the first effort to link the RV biomechanics to the organ function, but the relationships examined were limited. The present study investigated the relations of the RV tissue mechanics and a variety of organ function indices measured in large animal (ovine) species. The anatomy and physiology of sheep are closer to human patients compared with the small animals, and thus the findings here are more translatable to human physiology and cardiac biomechanics $[10,16,17]$. 

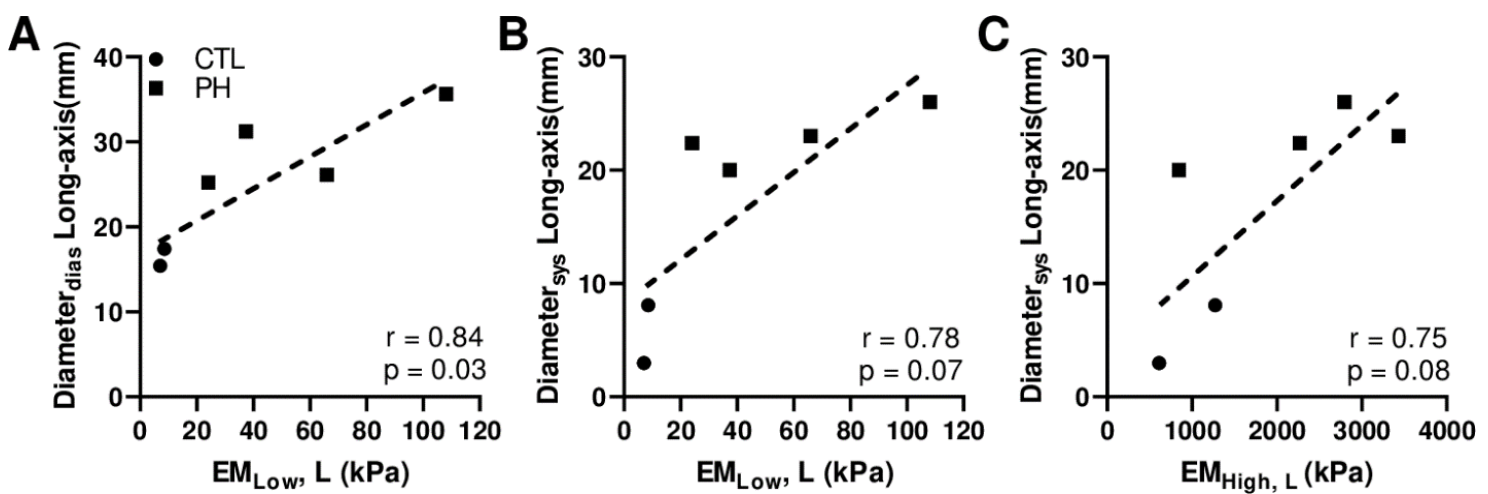

Figure 3. Correlations between the RV passive elasticity and RV diameter at longitudinal direction. (A) correlation between the EM at low strain range and RV end-diastolic diameter, (B-C) correlations between the EM and RV end-systolic diameter at low and high strain ranges, respectively.
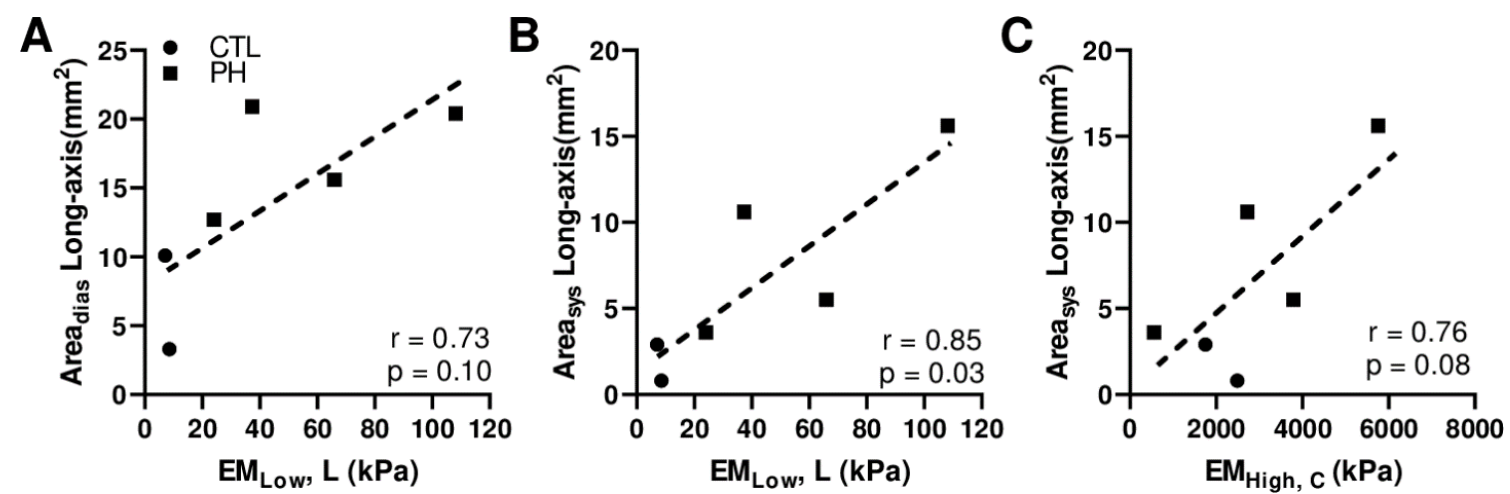

Figure 4. Correlations between the RV passive elasticity and the RV area. (A) correlation between the EM at low strain range and RV end-diastolic area at the longitudinal direction, (B) correlation between the EM and RV end-systolic area at low strain range at the longitudinal direction, and (C) correlation between the circumferential EM at high strain range and RV endsystolic area in the long axis.
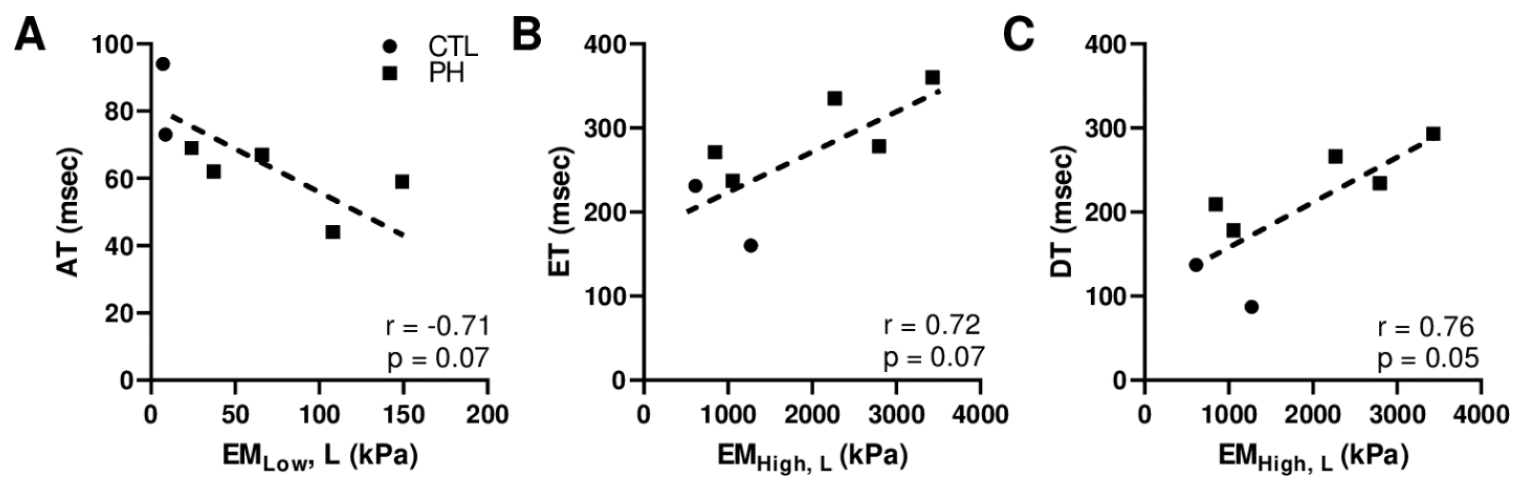

Figure 5. Correlations between the RV passive elasticity and RV hemodynamics. (A) correlation between the low-strain EM and RV acceleration time (AT); (B) correlation between the high-strain EM and RV ejection time (ET) and (B) correlation between the high-strain EM and RV deceleration time (DT).

We observed several interesting correlations that support the hypothesis that there is linkage between the RV mechanics and hemodynamic function. First, our results showed that the RV elasticity was correlated with the RV chamber geometry, which is an alternative index of RV function and a useful prognostic parameter for RV failure patients $[9,18-20]$. Our data showed that the longitudinal $\mathrm{EM}_{\text {Low }}$ was correlated with the RV end-diastolic diameter and area in the same direction (long axis) (Figures 3 and 4). The finding is consistent with the report in a pulmonary arterial banding rat study, which showed that the longitudinal $\mathrm{EM}_{\text {Low }}$ was correlated with the RV end-diastolic volume [8]. It is unclear whether the same degree of RV failure was achieved in the present ovine study as in the previous rodent study. Moreover, we have various durations of $\mathrm{PAC}$ in the $\mathrm{PH}$ sheep, which may include different stages of RV failure in the animals. Nevertheless, both our study and the previous study identified a correlation between the low-strain EM ( $\left.\mathrm{EM}_{\mathrm{Low}}\right)$ and RV diastolic geometry (Figures $3 \mathrm{~A}$ and $4 \mathrm{~A})$. These findings confirm a critical role of RV passive mechanical property in the diastolic function.

Furthermore, we observed a change in the anisotropic behavior of the RV during PH development (Figure 2). The stiffening of the $\mathrm{RV}$ in the longitudinal direction and the absence of stiffening in the circumferential direction led to a more anisotropic behavior of the RV with the progression of $\mathrm{PH}$. We speculate that the biaxial mechanical changes may partially explain the development of RV failure. Under persistent pressure overload, the RV typically remodels into a spherical shape and requires a higher wall strength in the circumferential direction 
to maintain the blood flow in the pulmonary circulation. Alternatively, a failure to enhance the circumferential wall strength will impair the ventricular function and result in RV failure. Therefore, a lack of stiffening ('elastic recoil strength') of the wall in the circumferential direction, as we observed in the study, may contribute to the decline of the in vivo function (e.g., decreased SV).

Next, we also observed new correlations between the RV passive elasticity and its systolic geometry (Figures 3B-C and 4B-C). This drove us to think how RV passive elasticity may interfere with the overall function including the systolic function. It is known that the myocardial stiffness plays a role in the progression of heart failure [21]. For the RV particularly, the diastolic stiffness derived from the diastolic pressurevolume relation is a better parameter than the systolic parameter such as the load-independent contractility to distinguish different clinical outcomes (survival) of $\mathrm{PH}$ patients [22]. This evidence underscores the importance of RV passive stiffness in the overall health of the RV. Our data here add additional support that the role of the passive elasticity may go beyond the diastolic function, and one possible explanation is that the matrix 'stiffness' may be linked with the 'health' state of the cardiomyocytes [23,24], and thus affect the contractile function of the RV. The understanding of the roles of active (systolic) and passive (diastolic) mechanical property in myocardial function has been an ongoing research area, especially with the development of non-invasive cardiac imaging and computational modeling techniques [25-27]. Therefore, future study should elucidate the linkage between the active and passive stiffness of the RV and their impacts on the RV function.

Finally, we observed for the first time that the longitudinal stiffness indices $\left(\mathrm{EM}_{\mathrm{Low}}\right.$ and $\left.\mathrm{EM}_{\mathrm{High}}\right)$ tended to be correlated with the AT $(\mathrm{p}=0.07)$ and DT $(\mathrm{p}=0.05)$ (Figure 5), both of which are hemodynamic indices associated with the ventricular afterload [28,29]. Unlike the AT, the DT is not a commonly reported hemodynamic parameter. A study in the LV showed that the increased DT was correlated with increased central blood pressure as well as with the increased pulse wave velocity (indicator of arterial stiffness) at rest and during exercise [29]. Therefore, the DT is suggested as a surrogate marker for central hemodynamics, mainly representing LV afterload (both steady and pulsatile). To our knowledge, such measurement in the RV has not been noted, but another group has measured the mid-systolic DT (the deceleration time from the peak to 'notch' in the flow profile) in pulmonary arterial hypertension patients. They found that the midsystolic DT was associated with the pulmonary vascular resistance and pulmonary pressure, which are measures of the steady RV afterload [30]. Therefore, our observed trends of correlations indicate that the $\mathrm{RV}$ longitudinal stiffening is an adaptation to the increased afterload, and the hemodynamic indices (AT and DT) may not only be used to estimate the RV afterload, but also to predict the ventricular wall stiffening.

In addition, the $\mathrm{EM}_{\mathrm{Low}}$ is a measurement in the diastolic stress range and thus it has been adopted as the diastolic stiffness of the RV [8,31]. It is speculated that the $\mathrm{EM}_{\text {Low }}$ is mainly contributed by the myofiber stiffness, which is different than the $\mathrm{EM}_{\text {High }}$ that is measured in the high-strain range and contributed mostly by the collagen fiber stiffness $[8,32,33]$. We do not know why $\mathrm{EM}_{\text {Low }}$ and $\mathrm{EM}_{\text {High }}$ showed different degrees of correlations with the AT and DT, and future study should investigate if RV stiffening in different strain ranges may distinguish adaptive and maladaptive remodeling or is a response to different types of RV afterload (steady or pulsatile). Overall, the suggested relations between the pulmonary hemodynamics and RV passive elasticity may imply new diagnostic markers for the assessment of RV function and should be further investigated in future preclinical and clinical studies.

\section{Conclusions}

In this study, we performed the in vivo RV function assessment and ex vivo $\mathrm{RV}$ mechanical measurements in healthy and $\mathrm{PH}$ ovine, and then investigated the relationship between the passive elasticity and RV function. We observed that the RV longitudinal elasticity was significantly correlated with the RV end-diastolic and end-systolic diameter/area, indicating a contribution of RV passive stiffness in the diastolic function. More importantly, the elastic modulus at the low strain range was correlated with the acceleration time, whereas the elastic modulus at the high strain range was correlated with the deceleration time. This suggests that the RV hemodynamic profile may be an alternative estimation of RV passive elasticity and can be explored as a useful marker for RV failure assessment. Overall, this study highlights the importance of the passive elastic properties of the $\mathrm{RV}$ in the progression of RV dysfunction.

\section{Acknowledgement}

We would like to thank Dr. Adam. Chicco for the valuable discussion about the correlations.

\section{References}

1. Konstam MA, Kiernan MS, Bernstein D, Bozkurt B, Jacob M, et al. (2018) Evaluation and Management of Right-Sided Heart Failure: A Scientific Statement from the American Heart Association. Circulation 137: 578-622. [Crossref]

2. Lahm T, Douglas IS, Archer SL, Bogaard HJ, Chesler NC, et al. (2018) Assessment of right ventricular function in the research setting: Knowledge gaps and pathways forward an official American thoracic society research statement. Am J Respir Crit Care Med 198: e15-e43. [Crossref]

3. Köhler D, Arnold R, Loukanov T, Gorenflo M (2013) Right Ventricular Failure and Pathobiology in Patients with Congenital Heart Disease - Implications for Long-Term Follow-Up. Front Pediatr 1: 37. [Crossref]

4. Haddad F, Hunt SA, Rosenthal DN, Murphy DJ (2008) Right ventricular function in cardiovascular disease, part I: Anatomy, physiology, aging, and functional assessment of the right ventricle. Circulation 117: 1436-1448. [Crossref]

5. Voelkel NF, Quaife RA, Leinwand LA, Barst RJ, Mcgoon MD, et al. (2006) Righ ventricular function and failure: report of a National Heart, Lung, and Blood Institute working group on cellular and molecular mechanisms of right heart failure. Circulation 114: 1883-1891. [Crossref]

6. Cansız FBC, Dal H, Kaliske M (2015) An orthotropic viscoelastic material model for passive myocardium: theory and algorithmic treatment. Comput. Methods Biomech Biomed Engin 18: 1160-1172. [Crossref]

7. Liu W, Wang Z (2019) Current Understanding of the Biomechanics of Ventricular Tissues in Heart Failure. Bioengineering 7: 2. [Crossref]

8. Jang S, Vanderpool RR, Avazmohammadi R, Lapshin E, Bachman TN, et al. (2017) Biomechanical and Hemodynamic Measures of Right Ventricular Diastolic Function: Translating Tissue Biomechanics to Clinical Relevance. J Am Heart Assoc 6: e006084. [Crossref]

9. Cheatham ML, Nelson LD, Chang MC, Safcsak K (1998) Right ventricular enddiastolic volume index as a predictor of preload status in patients on positive endexpiratory pressure. Crit Care Med 26: 1801-1806. [Crossref]

10. Camacho P, Fan H, Liu Z, He JQ (2016) Large Mammalian Animal Models of Heart Disease. J Cardiovasc Dev Dis 3: 30. [Crossref]

11. Nguyen-Truong M, Liu W, Boon J, Nelson B, Easley J, et al. (2020) Establishment of adult right ventricle failure in ovine using a graded, animal-specific pulmonary artery constriction model. Anim Model Exp Med 1: 11.

12. Wang Z, Chesler NC (2013) Pulmonary vascular mechanics: Important contributors to the increased right ventricular afterload of pulmonary hypertension. Exp Physiol 98: 1267-1273. [Crossref]

13. Labus KM, Puttlitz CM (2016) An anisotropic hyperelastic constitutive model of brain white matter in biaxial tension and structural-mechanical relationships. J Mech Behav Biomed Mater 62: 195-208. 
14. Witzenburg C, Raghupathy R, Kren SM, Taylor DA, Barocas VH (2012) Mechanical changes in the rat right ventricle with decellularization. $J$ Biomech 45: 842-849. [Crossref]

15. Javani S, Gordon M, Azadani AN (2016) Biomechanical Properties and Microstructure of Heart Chambers: A Paired Comparison Study in an Ovine Model. Ann Biomed Eng 44: 3266-3283. [Crossref]

16. Dixon JA, Spinale FG (2009) Large animal models of heart failure; A critical link in the translation of basic science to clinical practice. Circ Hear Fail 2: 262-271. [Crossref]

17. Pham T, Sun W (2012) Comparison of biaxial mechanical properties of coronary sinus tissues from porcine, ovine and aged human species. J Mech Behav Biomed Mater 6 : 21-29. [Crossref]

18. Cioffi G, de Simone G, Mureddu G, Tarantini L, Stefenelli C (2007) Right atrial size and function in patients with pulmonary hypertension associated with disorders of respiratory system or hypoxemia. Eur J Echocardiogr 8: 322-331. [Crossref]

19. Diebel LN, Wilson RF, Tagett MG, Kline RA (1992) End-Diastolic Volume: A Better Indicator of Preload in the Critically Ill. Arch Surg 127: 817-822. [Crossref]

20. Durham R, Neunaber K, Vogler G, Shapiro M, Mazuski J (1995) Right Ventricular End-Diastolic Volume as a Measure of Preload. J Trauma Acute Care Surg 39: 218 223. [Crossref]

21. Zile MR, Baicu CF, Ikonomidis JS, Stroud RE, Nietert PJ, et al. (2015) Myocardia stiffness in patients with heart failure and a preserved ejection fraction: contributions of collagen and titin. Circulation 131: 1247-1259. [Crossref]

22. Trip P, Rain S, Handoko ML, van der Bruggen C, Bogaard HJ, et al. (2015) Clinical relevance of right ventricular diastolic stiffness in pulmonary hypertension. Eur Respir $J$ 45: 1603-1612. [Crossref]

23. Forte G, Pagliari S, Ebara M, Uto K, Tam JK, et al. (2012) Substrate stiffness modulates gene expression and phenotype in neonatal cardiomyocytes in vitro. Tissue Eng Part A 18: 1837-1848. [Crossref]

24. Efraim Y, Schoen B, Zahran S, Davidov T, Vasilyev G, et al. (2019) 3D Structure and Processing Methods Direct the Biological Attributes of ECM-Based Cardiac Scaffolds. Sci Rep 9: 5578
25. Krishnamurthy A, Villongco C, Beck A, Omens J, McCulloch A (2015) Left Ventricular Diastolic and Systolic Material Property Estimation from Image Data: LV Mechanics Challenge. Stat Atlases Comput Models Heart 8896: 63-73. [Crossref]

26. Wang ZJ, Wang VY, Bradley CP, Nash MP, Young AA, et al. (2018) Left Ventricular Diastolic Myocardial Stiffness and End-Diastolic Myofibre Stress in Human Heart Failure Using Personalised Biomechanical Analysis. J Cardiovasc Transl Res 11: 346356. [Crossref]

27. Bermejo J, Yotti R, Pérez del Villar C, del Álamo JC, Rodríguez-Pérez D, et al. (2013) Diastolic chamber properties of the left ventricle assessed by global fitting of pressurevolume data: improving the gold standard of diastolic function. J Appl Physiol 115: 556-568. [Crossref]

28. Patel MD, Breatnach CR, James AT, Choudhry S, McNamara PJ, et al. (2019) Echocardiographic Assessment of Right Ventricular Afterload in Preterm Infants: Maturational Patterns of Pulmonary Artery Acceleration Time Over the First Year of Age and Implications for Pulmonary Hypertension. J Am Soc Echocardiogr 32: 884894.e4. [Crossref]

29. Cho IJ, Shim CY, Moon SH, Lee HJ, Hong GR, et al. (2017) Deceleration time of left ventricular outflow tract flow as a simple surrogate marker for central haemodynamics at rest and as well as during exercise. Eur Heart J Cardiovasc Imaging 18: 568-575. [Crossref]

30. Takahama H, McCully RB, Frantz RP, Kane GC (2017) Unraveling the RV Ejection Doppler Envelope: Insight Into Pulmonary Artery Hemodynamics and Disease Severity. JACC Cardiovasc Imaging 10: 1268-1277. [Crossref]

31. Fatemifar F, Feldman MD, Oglesby M, Han HC (2018) Comparison of Biomechanica Properties and Microstructure of Trabeculae Carneae, Papillary Muscles, and Myocardium in the Human Heart. J Biomech Eng 141: 0210071-02100710. [Crossref]

32. Voorhees AP, Han HC (2015) Biomechanics of Cardiac Function. Compr Physiol 5 1623-1644. [Crossref]

33. Avazmohammadi R, Hill MR, Simon MA, Zhang W, Sacks MS (2017) A nove constitutive model for passive right ventricular myocardium: evidence for myofibercollagen fiber mechanical coupling. Biomech Model Mechanobiol 16: 561-581. [Crossref]

Copyright: (C2020 Liu W. This is an open-access article distributed under the terms of the Creative Commons Attribution License, which permits unrestricted use, distribution, and reproduction in any medium, provided the original author and source are credited. 